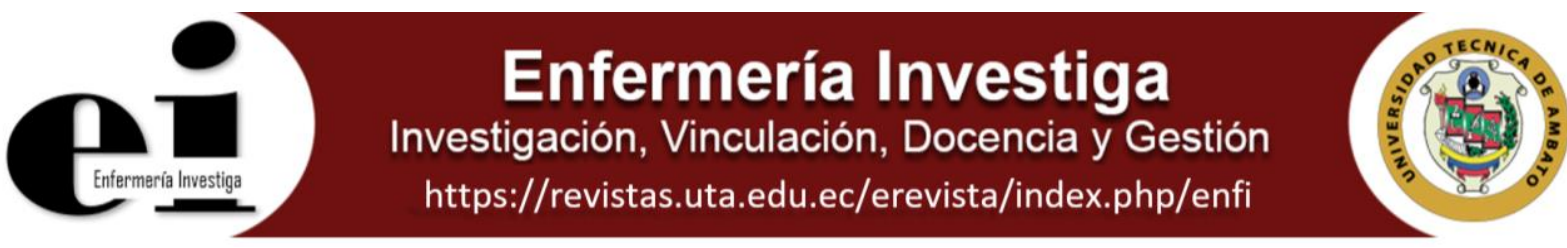

\title{
COMPLICACIONES EN NEONATOS DE MADRES DIAGNOSTICADAS DE ZIKA EN EL DISTRITO 09D01 ZONAL 8 DE SALUD DE LA CIUDAD DE GUAYAQUIL
}

\section{COMPLICATIONS IN NEWBORNS OF DIAGNOSED MOTHERS OF ZIKA DURING PREGNANCY IN THE 09D01 HEALTH ZONE 8 DISTRICT OF THE CITY OF GUAYAQUIL}

Marianita Grisela Méndez Caicedo1 https://orcid.org/0000-0002-0631-4364, Wladimir Alexander Hinojosa Méndez² https://orcid.org/0000-0002-0267-0513, Dávila Tapia Pedro José3https://orcid.org/0000-0001-8168-6523

1 Universidad Peruana Unión, Lima Perú.

${ }^{2}$ Hospital Delfina Torres de Concha, Esmeraldas Sur, Ecuador.

${ }^{3}$ Universidad de Guayaquil, Ecuador.

2477-9172 / 2550-6692 Derechos Reservados ( 2020 Universidad Técnica de Ambato, Carrera de Enfermería. Este es un artículo de acceso abierto distribuido bajo los términos de la Licencia Creative Commons, que permite uso ilimitado, distribución y reproducción en cualquier medio, siempre que la obra original es debidamente citada.

Enviado: 01 de octubre 2020

Aceptado: 28 de noviembre 2020

\section{RESUMEN}

Introducción: la infección por el virus del Zika es un problema de salud pública por las complicaciones neonatales de moderada y grave severidad. Objetivo: establecer las complicaciones en los neonatos de madres diagnosticadas con Zika. Metodología: investigación cuantitativa, no experimental, descriptiva, con una muestra de 82 neonatos de madres con infección de virus del Zika, datos obtenidos del departamento de estadísticas del Distrito 09D01, durante el periodo enero 2017 a enero 2018, procesados por el software SPSS Estatistics 24.0 para windows, con una distribución numérica y porcentual, con la prueba de $T$ de Student se estableció la significancia estadística $(p<0.05)$. Resultados: En los 82 neonatos de madres infectadas con el virus Zika 52 casos $(63,4 \%)$ nacieron por cesárea y 30 casos $(36,59 \%)$ por parto vaginal, 76 casos $(92,68 \%)$ nacieron vivos y 6 casos $(7,3 \%)$ mortinatos, con igual proporción de neonatos pretérminos y a términos, microcefalia en 13 casos $(15,88 \%)$, seguido de hiperbilirrubinemia en 5 casos $(6,10 \%)$ e hipotiroidismo en 3 casos (3,66\%), con una diferencia significativa $(p<0,05)$ en la microcefalia en relación a las otras complicaciones. Conclusiones: Se evidenció un predominio en el tipo de parto por cesáreas, aunque diversos consensos internacionales establecen que la infección por el virus Zika o la microcefalia no son indicaciones, por lo que la cesárea se realizará solo por motivos obstétricos exclusivamente. En los neonatos existió igual proporción en la edad gestacional y se evidenciaron complicaciones como microcefalia, hiperbilirrubinemia e hipotiroidismo predominando la microcefalia en relación a las otras complicaciones.

Palabras Clave: Zika; neonatos; gestantes, malformaciones, microcefalia, mortalidad.

\section{ABSTRACT}

Introduction: Zika virus infection is a public health problem due to moderate and severe neonatal complications. Objective: to establish the complications in the neonates of mothers diagnosed with Zika. Methodology: quantitative, nonexperimental, descriptive research, with a sample of 82 neonates of mothers with Zika virus infection, data obtained from the statistics department of District 09D01, during the period January 2017 to January 2018, processed by the software SPSS Statistics 24.0 for windows, with a numerical and percentage distribution, with the Student's t test statistical significance was established $(p<0.05)$. Results: In the 82 neonates of mothers infected with the Zika virus, 52 cases $(63.4 \%)$ were born by cesarean section and 30 cases (36.59\%) by vaginal delivery, 76 cases $(92.68 \%$ ) were born alive and 6 cases $(7.3 \%)$ were stillborn, with the same proportion of preterm and full term neonates, microcephaly in 13 cases $(15.88 \%)$, followed by hyperbilirubinemia in 5 cases $(6.10 \%)$ and hypothyroidism in 3 cases $(3.66 \%)$, with a significant difference $(p<0.05)$ in microcephaly in relation to the other complications. Conclusions: There was evidence of a predominance in the type of cesarean delivery, although various international consensuses made that infection by the Zika virus or microcephaly are not indications, so that cesarean section is performed only for obstetric reasons exclusively. In neonates there was an equal proportion in gestational age and complications such as microcephaly, hyperbilirubinemia and hypothyroidism were evidenced, with microcephaly predominating in relation to the other complications

Keywords: Zika; neonates; pregnant; malformations; microcephaly; the mortality. 


\section{INTRODUCCIÓN}

En la actualidad, una de las enfermedades que mayor impacto y problemas generan, a nivel del área de salud pública, es la infección causada por el virus del Zika, la cual se ha desarrollado de manera epidémica a nivel mundial, con prevalencia en países latinoamericanos (1-3). La infección por el virus del Zika se evidenció por primera vez en África, en Uganda,en el año 1947 en la selva de Zika, esta patología no fue descrita en humanos hasta el año 1954 en Nigeria (4-6).

Sin embargo, los primeros brotes de esta enfermedad, aparecieron en el año 2007 en la isla Yap en Micronesia, donde se registraron aproximadamente 108 casos, de los cuales 72 se consideraron sospechosos. La Organización Panamericana de la Salud, informó que durante el brote que ocurrió en Polinesia, en el año 2015 se reportaron y detallaron el desarrollo de complicaciones muy graves neurológicas, autoinmunes y cardiacas $(6,8)$

El dengue, chikungunya y zika son enfermedades del grupo de las arbovirosis, transmitidas por los vectores Aedes aegypti y Aedes albopictus, que representan un problema grave a nivel mundial, debido a que su prevención implica también la vigilancia de sus vectores, lo que hace difícil su control y casi imposible evitar su expansión a cualquier país tropical o subtropical e incluso algunas regiones templadas, como América, Asia, África con predominio en las costas del Pacifico, con una notable adaptación a entornos urbanos y peridomésticos (9-13). No se ha demostrado, la transmisión directa del virus por mordeduras de animales a humanos.

En la actualidad se han registrado otras vías de transmisión del Zika, como la sexual, infecciones perinatales e intrauterina, provocando un grave problema de salud pública (14-15). La propagación del Zika no ha logrado detenerse, puesto que en numerosos estudios se ha evidenciado que el virus posee una gran capacidad de propagación, con mayor énfasis en lugares de climas cálidos y húmedos (16-19), también se ha demostrado de igual manera que la transmisión no solamente se produce del mosquito infectado a humano, sino que la picadura de un mosquito hacia un humano ya portador de Zika, permite la transmisión del mismo, de esta manera, se incrementa en gran cantidad su capacidad alcanzar niveles de epidemia (12-18).

Las malformaciones fetales han sido descritas en infecciones virales como la rubéola, citomegalovirus, herpes simple tipo 1 y 2 y en la actualidad por el virus Zika, sin embargo, existen virus que no atraviesan la barrera placentaria y por tanto, no producen daño en el embrión ni al el feto. La placenta humana tiene varias líneas de defensa contra las infecciones virales, las cuales van desde una barrera física de sincitios multinucleados a una respuesta inmune innata y adaptativa. La asociación entre virus Zika y las anormalidades fetales ha requerido de diversos estudios y la evidencia actual sugiere que al igual que el citomegalovirus ha desarrollado distintas formas para superar la defensa trofoblástica, con una predilección por el tejido neuronal fetal, causando anormalidades en el neurodesarrollo. La activación del sistema inmune materno por infecciones, factores tóxicos y ambientales, pueden afectar la gestación e incrementar el riesgo a desarrollar malformaciones congénitas. (19-21)

Las mujeres embarazadas no difieren de otros grupos poblacionales en cuanto a la frecuencia de las complicaciones, pero al ser una virosis con alta afinidad por tejido nervioso, las afectaciones en el sistema nervioso central y periférico, tanto de la madre como el feto pueden verse comprometidos en grado muy variable, que dependerán de la virulencia viral, de la carga viral, de la susceptibilidad y de la respuesta inmunológica personal. Dentro de las complicaciones encontramos las siguientes: complicaciones neurológicas: encefalitis, parestesias, meningoencefalitis, parálisis facial y mielitis. Complicaciones autoinmunes: Síndrome de Guillain Barré, púrpura trombocitopenia (22). Las complicaciones fetales: microcefalia, microftalmia, calcificaciones intraoculares, intracraneales e intrahepáticas, patología de fosa craneal posterior, muerte embrionaria o fetal y abortos (23-25).

No existe evidencia de que la mujer embarazada sea más susceptible al contagio o de que cause una enfermedad más grave en estas, recientemente se ha demostrado la relación entre el virus del Zika y la microcefalia infectando a ratones hembras embarazadas con dos cepas víricas diferentes, una procedente de África y otra de Brasil. Al terminar el período de gestación los recién nacidos presentaban signos de microcefalia. (26-30), motivo por el cual, el objetivo es establecer las complicaciones que se presentan en los neonatos de madres diagnosticadas con Zika.

\section{MÉTODOS.}

Se realizó un estudio cuantitativo, transversal, descriptivo, no experimental y retrospectivo, utilizando como fuente de información una base de datos compuesta por pacientes hijos de madres ingresadas bajo el código de diagnóstico CIE-10 U06.9, correspondiente a Infección o fiebre del zika, provista por el Departamento de Estadísticas del Distrito 09D01 correspondiente a la Zona 8, de la ciudad de Guayaquil, en la cual constaban los números de las historias clínicas de todos las pacientes que fueron evolucionadas bajo dicho código, en el sistema correspondiente al Distrito de Salud, el que forma parte de la red de atención primaria del Ministerio de Salud Pública de Ecuador, los cuales contenían la información, tanto epidemiológica como clínica, de todas las pacientes atendidas bajo este diagnóstico dentro del período de estudio.

Criterios De Inclusión: neonatos nacidos de madres que en período de gestación se realizó diagnóstico de infección por virus Zika, mediante la prueba confirmatoria de la reacción en cadena de la polimerasa transcriptasa inversa (RTPCR), para la detección de ARN viral, la muestra de sangre se tomó hasta el 5to día de iniciada el cuadro clínico (31).

\section{Criterios de Exclusión:}

a. Neonatos nacidos de gestantes quienes hayan sido diagnosticados de otra patología diferente a Zika que pueda causar malformaciones congénitas

b. Pacientes quienes fueron transferidos o quienes se les perdió el seguimiento.

Los datos obtenidos fueron procesados a través del software estadístico (SPSS Estatistics 24.0 para windows), aplicando el análisis estadístico, por medio del cálculo de la distribución numérica, porcentual y por medio de la prueba de T de Student se estableció la significancia estadística $(p<0.05)$.

\section{Consideraciones Éticas}

Se solicitó aprobación del departamento de estadística del en el distrito 09d01 correspondiente a la zona 8, de la ciudad de Guayaquil, con el fin de que conocieran los objetivos del estudio y la metodología preestablecida para analizar los datos de investigación y se tramitó los permisos necesarios para la obtención de datos y su posterior análisis. Se acordó mantener confidencialidad de los nombres de los pacientes estudiados, con el fin de preservar el principio bioético de la beneficencia.

\section{RESULTADOS}

En la distribución de los de los 82 neonatos nacidos de madres infectadas con el virus Zika de acuerdo al tipo de parto se evidenció 52 casos $(63,4 \%)$ parto por cesárea y 30 casos $(36,6$ $\%)$ por parto por vía vaginal, con una diferencia significativa $(p<0,05)$ en el parto por cesárea (tabla 1). 
Tabla 1

Tipo de parto de las madres infectadas con el virus Zika

\begin{tabular}{lcc}
\hline Tipo de parto & $\mathrm{N}^{\circ}$ & $\%$ \\
\hline Vaginal & 30 & $36,6^{*}$ \\
Cesárea & 52 & 63,4 \\
\hline Total & 82 & 100 \\
\hline
\end{tabular}

Fuente. Base de Datos Distrito 09D01, Zona 8.

$\mathrm{p}<0,05$

En la condición al nacimiento de los neonatos de madres infectadas con el virus Zika 76 (92,7 \%) nacieron vivos y 6 casos (7,3\%) mortinatos (tabla 2).

\section{Tabla 2}

Condición al nacimiento de neonatos con madres infectadas con el virus Zika

\begin{tabular}{lcc}
\hline $\begin{array}{l}\text { Condición del neonato al } \\
\text { nacimiento }\end{array}$ & $\mathrm{N}^{\circ}$ & $\%$ \\
\hline Vivo & 76 & 92,7 \\
Mortinato & 6 & 7,3 \\
\hline Total & 82 & 100 \\
\hline
\end{tabular}

Fuente. Base de Datos Distrito 09D01, Zona 8. 
En la edad gestacional de los neonatos de madres infectadas con el virus Zika existió igual proporción de pre-término y a término en un $50 \%$ (tabla 3 )

\section{Tabla 3}

\section{Edad gestacional de los neonatos de madres infectadas con el virus Zika}

\begin{tabular}{llc}
\hline Edad Gestacional & $\mathrm{N}^{\circ}$ & $\%$ \\
\hline Pretérmino & 41 & 50,0 \\
A término & 41 & 50,0 \\
\hline Total & 82 & 100 \\
\hline
\end{tabular}

Fuente: Base de Datos Distrito 09d01, Zona 8.

En la distribución según el sexo de los neonatos de madres infectadas con el virus Zika 53 casos (64,7\%) de sexo masculino y 29 casos $(35,3 \%)$ sexo femenino (tabla 4$)$.

\section{Tabla 4}

\section{Sexo de los neonatos de madres infectadas con el virus Zika}

\begin{tabular}{lll}
\hline Sexo & $\mathrm{N}^{\circ}$ & $\%$ \\
\hline Masculino & 53 & 64,7 \\
Femenino & 29 & 35,3 \\
\hline Total & 82 & 100 \\
\hline
\end{tabular}

Fuente. Base de datos distrito 09d01, Zona 8

En la distribución de las complicaciones evidenciadas en los neonatos posterior al nacimiento, se reportó 61 casos (74,39\%) que no desarrollaron complicaciones posteriores al nacimiento, microcefalia en 13 casos $(15,9 \%)$, seguido de hiperbilirrubinemia en 5 casos $(6,1 \%)$ e hipotiroidismo en 3 casos $(3,7 \%)$, con una diferencia significativa $(p<0,05)$ en la microcefalia en relación a las otras complicaciones (tabla 5 ) 
Tabla 5

Complicaciones de los neonatos de las madres infectados con el

virus Zika

\begin{tabular}{lcc}
$\begin{array}{l}\text { Complicaciones } \\
\text { neonatales }\end{array}$ & $\mathrm{N}^{\circ}$ & $\%$ \\
\hline Hipotiroidismo & 3 & 3,7 \\
Microcefalia & 13 & $15,9^{*}$ \\
Hiperbilirrubinemia & 5 & 6,1 \\
Sin complicaciones & 61 & 74,3 \\
\hline Total & 82 & 100 \\
\hline
\end{tabular}

Fuente. Base de Datos Distrito 09D01, Zona 8.

*p $<0,05$

El perímetro cefálico del neonato producto de madres infectadas por el virus Zika, se evidenció de los 82 casos, 13 (15,9\%) presentaron microcefalia, mientras que los 69 casos restantes (84,1\%), tuvieron un perímetro cefálico normal (tabla 6)

\section{Tabla 6}

Circunferencia cefálica en neonatos nacidos de madres infectadas con

el virus Zika

\begin{tabular}{lcc}
\hline $\begin{array}{l}\text { Circunferencia } \\
\text { cefálica }\end{array}$ & frecuencia & Porcentaje \\
\hline Microcefalia & 13 & 15,9 \\
Normal & 69 & 84,1 \\
\hline Total & 82 & 100 \\
\hline
\end{tabular}

Fuente: Base de Datos Distrito 09D01, Zona 8.

En la relación entre edad gestacional neonatal y las complicaciones post-natales existió una distribución equitativa con respecto al nacimiento a término y pretérmino, con un predominó de la microcefalia en ambos tipos de edad gestacional (tabla 7). 


\section{Tabla 7}

\section{Relación entre edad gestacional neonatal y complicaciones post-} natales

\begin{tabular}{|c|c|c|c|c|c|c|}
\hline \multirow[b]{2}{*}{$\begin{array}{l}\text { Edad } \\
\text { Gestacional }\end{array}$} & \multicolumn{6}{|c|}{ Complicaciones post-natales } \\
\hline & Hiperbilirrubinemia & Hipotiroidismo & Microcefalia & Ninguna & Total & $\%$ \\
\hline A término & 3 & & 7 & 31 & 41 & 50,0 \\
\hline Pretérmino & 2 & 3 & 6 & 30 & 41 & 50,0 \\
\hline Total & 5 & 3 & 13 & 61 & 82 & 100 \\
\hline
\end{tabular}

Fuente: Base de Datos Distrito 09D01, Zona 8.

\section{DISCUSIÓN:}

En la investigación actual en el tipo de parto de las madres infectadas con el virus Zika se evidenció un predominio el parto por cesárea, a diferencia de Díaz G donde el 50 \% la vía de nacimiento fue vaginal, un $48 \%$ cesárea, la Sociedad Española de Ginecología, la Sociedad Española de Infectología Pediátrica y la Sociedad Española de Neonatología y la guía para la vigilancia integrada del Zika del Ministerio de Salud de Colombia, establecen que no existe ninguna indicación para cambiar la vía de parto vaginal, es decir, la infección por el virus Zika o la microcefalia no son indicaciones de cesárea, resaltando que la cesárea innecesaria aumenta el riesgo de complicaciones tanto para la madre como para el bebé, por lo que la cesárea se realizará solo por motivos obstétricos exclusivamente $(32,33)$.

En estudio actual la condición al nacimiento de los neonatos de madres infectadas con el virus Zika se presentaron 6 casos de mortinatos, a diferencia de los resultados de De Oliveira et al., que establecieron tres casos de mortinatos, es decir, una tasa de mortalidad perinatal del 27,3\% (34), Pomar et al., y Shiu et al., evidenciaron $2,3 \%$ de mortinatos $(35,36)$ y González-Méndez et al, reportaron 1 óbito por parto pretérmino de $700 \mathrm{~g}$, secundario a insuficiencia ístmico cervical y 1 aborto en el primer trimestre del embarazo, ocurrido a las 7.5 semanas de gestación (37).

En los resultados de la presente investigación en los neonatos existió igual proporción en la edad gestacional, con 13 casos de microcefalia, a diferencia de los hallazgos de Van der Linden, donde 11 casos nacieron a término y dos fueron pretérminos, de igual manera Pomar $\mathrm{L}$, et al., encontraron un predominio de neonatos a términos (35), Díaz G, evidenciaron 6 casos un $5.5 \%$ con microcefalia (3), De Araujo establecieron 58 casos de microcefalia con $93 \%$ de calcificaciones principalmente en la unión cortical/subcortical, siguiendo la localización en la región periventricular, los ganglios basales, el tálamo, el mesencéfalo y el cerebelo, el $79 \%$ con malformaciones del desarrollo cortical, incluida la lisencefalia (insuficiencia del desarrollo de surcos y circunvoluciones cerebrales) asociada con paquigiria (presencia de pocas circunvoluciones amplias y lisas) y agiria (sin pliegues corticales) (38).

\section{CONCLUSIONES}

El tipo de parto de las madres infectadas con el virus Zika se evidenció un predominio el parto por cesárea, pero la Sociedad Española de Ginecología, la Sociedad Española de Infectología Pediátrica y la Sociedad Española de Neonatología y la guía para la vigilancia integrada del Zika del Ministerio de Salud de Colombia, establecen que no existe ninguna indicación para cambiar la vía de parto vaginal, es decir, la infección por el virus Zika o la microcefalia no son indicaciones de cesárea, por lo que la cesárea se realizará solo por motivos obstétricos exclusivamente.En los neonatos existió igual proporción en la edad gestacional y se evidenciaron complicaciones como microcefalia, hiperbilirrubinemia e hipotiroidismo predominando la microcefalia en relación a las otras complicaciones.

\section{RECOMENDACIONES}

1. Realizar protocolos y esquemas preventivos para casos del Síndrome congénito por virus Zika.

2. Las mujeres en estado de gestación deben evitar la exposición a zonas activas de la enfermedad durante el embarazo, con la finalidad de reducir la infección por virus del Zika.

3. Realizar a los neonatos control y seguimiento por parte de especialistas de la Red de Salud hasta un periodo edad de 5 años con la finalidad de detectar alteraciones tanto neurológicas, cognitivas

\section{REFERENCIAS}

1. Cofré Fernanda. Infección intrauterina por virus Zika y microcefalia. Rev. chil. infectol.2016;33(1): 96-96. https://scielo.conicyt.cl/scielo.php?script=sci_arttext\&pid=S0716-10182016000100018\&lng=es. 10182016000100018

2. Aspilcueta-Gho Daniel, Benites Villafane Carlos, Calderón Sánchez Martin Menel, Calderón Yberico José Gilmer. Infec el Perú: de amenaza a problema de salud. Rev. peru. ginecol. obstet. 2017;63(1):57-64. I http://www.scielo.org.pe/scielo.php?script=sci_arttext\&pid=S2304-51322017000100007\&lng=e 
3. Díaz G Al. Resultados maternos-fetales de pacientes diagnosticadas con Zika Hospitales Bertha Calderon Roque. Doct Nacional de Nicaragua, Managua. 2015.

4. Al-Afaleq Al. Zika Virus Disease [published correction appears in Saudi J Med Med Sci. 2017 May-Aug;5(2):197]. Saudi 2017;5(1):2-8. doi:10.4103/1658-631X.194260

5. Alvarado Socarras, Jorge L. Zika en neonatos: Todo no está dicho Revista de la Universidad Industrial de Sa 2016;48(2):160-162.

6. Coronell-Rodríguez Wilfrido, Arteta-Acosta Cindy, Suárez-Fuentes M. Alejandra, Burgos-Rolon M. Cecilia, Rubio-Sotom Sarmiento-Gutiérrez Michelle. Infección por virus del Zika en el embarazo, impacto fetal y neonatal. Rev. chil. infectol. 673. Disponible en: https://scielo.conicyt.cl/scielo.php?script=sci_artt 10182016000600009\&lng=es. http://dx.doi.org/10.4067/S0716-10182016000600009.

7. Rincón Silva NG, Acevedo Castro DA. Análisis general del brote epidemiológico causado por los virus Zika y chikungui Rev. Med. 2019;27(2): 47-62. Disponible en: https://revistas.unimilitar.edu.co/index.php/rmed/article/view/3606

8. Melo AS, Aguiar RS, Amorim MM, Arruda MB, Melo FO, Ribeiro ST, Batista AG, Ferreira T, Dos Santos MP, Sampaio Rabello LP, Gonzaga CE, Malinger G, Ximenes R, de Oliveira-Szejnfeld PS, Tovar-Moll F, Chimelli L, Silveira PP, Delv Campanati L, Nogueira RM, Filippis AM, Szejnfeld J, Voloch CM, Ferreira OC Jr, Brindeiro RM, Tanuri A. Congenital Zikc Beyond Neonatal Microcephaly. JAMA Neurol. 2016;73(12):1407-1416. doi: 10.1001/jamaneurol.2016.3720. PMID: 276

9. Real-Cotto Jhony Joe, Ochoa-Andrade Aurora, Maridueña-Silva Helen, Pacheco-Vila Lourdes Carolina, Vizueta-N Sánchez-Haz Néstor Neil. Caracterización epidemiológica del zika en mujeres atendidas en el distrito 09D01 de Gu científica INSPILIP V. 2017; 2(1):1-16

10. Milagros Romero De Fasolino, Andrés Fasolino Romero, María Liseth Hernández Rodríguez, Tibisay Rincón Ríos, Alisa Machín, Wilmer Noé Delgado Luengo. Conocimiento sobre la infección por el virus zika y su potencial teratogénico en primer año de medicina. Vitae: Academia Biomédica Digital. 2017; 70:1-10.

11. Morilla Guzmán Andrés Armando, Álvarez Fumero Roberto. Recomendaciones para la atención a hijos recién nacidos diagnóstico de virus Zika en Cuba. Rev Cubana Pediatr. 2017; 89(4):1-14. Di http://scielo.sld.cu/scielo.php?script=sci_arttext\&pid=S0034-75312017000400016\&lng=es

12. Van der Linden V, Pessoa A, Dobyns W, Barkovich AJ, Júnior HV, Filho EL, Ribeiro EM, Leal MC, Coimbra PP, Aragãc Ventura C, Ramos RC, Cruz DD, Cordeiro MT, Mota VM, Dott M, Hillard C, Moore CA. Description of 13 Infants Born 2015-January 2016 With Congenital Zika Virus Infection Without Microcephaly at Birth - Brazil. MMWR Morb Mi 2016;65(47):1343-1348. doi: 10.15585/mmwr.mm6547e2. PMID: 27906905.

13. Carod-Artal F.J. Epidemiología y complicaciones neurológicas de la infección por el virus del Zika: un nuevo virus neurotı Rev Neurol. 2016;62:317-328. PMID: 26988170

14. Licourt Otero Deysi, Saínz Padrón Leisi. Virus Zika: una alerta para la prevención: Zika virus: an alert for preventio Médicas. 2018;22(3):221-243. Disponible en: http://scielo.sld.cu/scielo.php?script=sci_artt $31942018000300023 \&$ Ing=es.

15. Zamora-Lares AN, Panduro-Barón JG, Pérez-Molina JJ, Quezada-Figueroa NA, González-Moreno J, Fajardo-Dueñas adolescentes y sus complicaciones materno perinatales. Revista Médica MD. 2013;4(4):234-238

16. Albinagorta Olórtegui Roberto, Díaz-Vela Maritza del Pilar. Salud fetal y diagnóstico ultrasonográfico en la infección peri zika. Rev. Perú. ginecol. obstet. 2017; 63(1):71-79. Disponible en: http://www.scielo.org.pe/scielo.php?script=sci_artt $51322017000100009 \&$ Ing $=$ es.

17. Socorrás Jorge L., Diaz-Quijano Fredi Alexander, Rodríguez-Morales Alfonso J. Diagnóstico diferencial de dengue y población pediátrica. Biomédica. 2016;36 (Supl. http://www.scielo.org.co/scielo.php?script=sci_arttext\&pid=S0120-41572016000600023\&lng=en

18. Cavalheiro S, Lopez A, Serra S, Da Cunha A, da Costa MD, Moron A, Lederman HM. Microcephaly and Zika neuroradiological aspects. Childs Nerv Syst. 2016;32(6):1057-60. doi: 10.1007/s00381-016-3074-6. Epub 2016 Apr 14. P PMCID: PMC4882355.

19. Sazo D Araneda. Zika en embarazo y resultado perinatal. Rev. méd. (Col. Méd. Cir. Guatem.) 2019;158(1):7-10 https://revistamedicagt.org/index.php/RevMedGuatemala/article/view/113

20. Eras Carranza, Janette Esther, Rivera Macachi Darwin Arnulfo, Solano Floreano Lilian Marisol Falconí Peláez, Arias Gumercinda, Blacio Rivas Ana Ubaldina. Caracterización de encefalitis por Zika y atención de enfermería: caso clí Investiga. 2018;3(4):223-227. Disponible en: <https://revistas.uta.edu.ec/erevista/index.php/enfi/article/view/390>.

21. Martínez-Pérez MI, CervantesQuiróz AR, Cacique-Sánchez C, Gómez-Bautista JB, HernándezPeláez DK, Matí Alteraciones del desarrollo neurológico en productos con infección gestacional por virus Zika. Avan C Salud Med. 2018

22. Chaves Loaiza E, Silva Díaz RF, Johynny Bernarda. Virus Zika en el embarazo. Rev.méd.sinerg. 2020;5(7):e533 https://revistamedicasinergia.com/index.php/rms/article/view/533

23. Panchaud A, Stojanov M, Ammerdorffer A, Vouga M, Baud D. Emerging Role of Zika Virus in Adverse Fetal and Neor Clin Microbiol Rev. 2016;29(3):659-94. doi: 10.1128/CMR.00014-16. PMID: 27281741; PMCID: PMC4978612.

24. Cabezas C, Donaires F. Enfoque sindrómico para el diagnóstico y manejo de enfermedades infecciosas febriles aguda de emergencia. Rev Peru Med Exp Salud Publica. 2017;34(2):316-22. doi: 10.17843/rpmesp.2017.342.2836

25. Alvarado-Socarras JI, Sepúlveda-Arias Jc, Zambrano Li, Rodríguez-Morales Aj. Importancia del diagnóstico de lab durante el embarazo y su posible asociacion con el sindrome de Guillain Barre. Medicina Clínica 2016;147(4):182-183

26. Joob Beuy, Wiwanitkit Viroj. Infección por el virus Zika en el embarazo y su impacto Infección por virus Zika en impacto. Rev. chil. infectol.2017; 34(2):194-194. Disponible en: https://scielo.conicyt.cl/scielo.php?script=sci_artt $10182017000200017 \&$ Ing=en. http://dx.doi.org/10.4067/S0716-10182017000200017. 
27. Del Carpio-Orantes, Luis; González-Clemente, María del Carmen Microcefalia y arbovirus Revista Médica del Institu Seguro Social. 2018;56(2). Disponible en: http://www.redalyc. org/articulo.oa?id=457754717015

28. Caylà JA, Domínguez Á, Rodríguez Valín E, de Ory F, Vázquez A, Fortuny C; Grupo de trabajo sobre Zika del Programe Vigilancia y Control de Enfermedades Transmisibles (PREVICET) del CIBER de Epidemiología y Salud Pública (' infección por virus Zika: una nueva emergencia de salud pública con gran impacto mediático [Zika virus infection: a nı emergency with great media impact]. Gac Sanit. 2016;30(6):468-471. Spanish. doi: 10.1016/j.gaceta.2016.05.015. Ep PMID: 27474488.

29. Lugones Botell Miguel, Ramírez Bermúdez Marieta. Infección por virus zika en el embarazo y microcefalia. Rev Cubana 2016;42(3):398-411. Disponible en: http://scielo.sld.cu/scielo.php?script=sci_arttext\&pid=S0138-600X2016000300015\&

30. Yagüe Pasamón R, Sagarra Mur D. Abordaje del paciente infectado por zika. Metas Enferm. 2016;19(6): 22-27.

31. Ministerio de Salud Pública del Ecuador. RESPUESTA FRENTE A LA ENFERMEDAD DEL VIRUS DE ZIKA EN EL E( Disponible en: https://www.salud.gob.ec/wp-content/uploads/2015/12/RESPUESTA-FRENTE-AL-ZIKA.pdf

32. Sociedad Española de Ginecología, Sociedad Española de Infectología Pediátrica, Sociedad Española de Neonatologí́ de manejo de la infección por virus zika durante el embarazo y en recién nacidos. 2017.

Disponible en: https://www.aeped.es/sites/default/files/documentos/procedimiento_manejo_conjunto_zika.pdf

33. Ministerio de Salud de Colombia. Guía para la vigilancia integrada de la infección por virus Zika y recomendaciones $p$ salud, 2016. http://www.ospeca.org.ar/descargas/zika-guia-para-equipos-de-salud.pdf

34. De Oliveira WK, Carmo EH, Henriques CM, et al. Zika Virus Infection and Associated Neurologic Disorders in Brazil 2017;376(16):1591-1593. doi:10.1056/NEJMc1608612

35. Pomar L, et al. Maternal-fetal transmission and adverse perinatal outcomes in pregnant women infected with Zika vi cohort study in French Guiana. BMJ 2018;363:k4431. http://doi.org/10.1136/bmj.k4431

36. Shiu C, et al. Zika virus testing and outcomes during pregnancy. Center for Disease Control and Prevention https://wwwnc.cdc.gov/eid/article/24/1/17-0979_article

37. González-Méndez RP, Fierros-Adame MM, Domínguez-Morales E, MartínezHernández CM. Desenlaces perinatales e de madres infectadas con el virus del Zika durante el embarazo. Ginecol Obstet Mex. 2019 agostc https://doi.org/10.24245/gom. v87i8.2858

38. De Araújo TVB, Ximenes RAA, Miranda-Filho DB, Souza WV, Montarroyos UR, de Melo APL, Valongueiro S, de Albu Braga C, Filho SPB, Cordeiro MT, Vazquez E, Cruz DDCS, Henriques CMP, Bezerra LCA, Castanha PMDS, Dhalia R, ETA, Martelli CMT, Rodrigues LC; Asociación entre microcefalia, infección por el virus del Zika y otros factores de $r$ informe final de un estudio de casos y controles. Lancet Infect Dis. 2018 marzo; 18 (3): 328-336. doi: 10.1016 / S1473-3 2. Publicación electrónica 201711 de diciembre. Errata en: Lancet Infect Dis. 4 de enero de 2018 ;: PMID: 29242091. 